\title{
REPÚBLICA Y PRIMER FRANQUISMO: LA MUJER ESPAÑOLA ENTRE EL ESPLENDOR Y LA MISERIA, 1930-1950
}

\author{
JOSÉ MANUEL DÍEZ FUENTES
}

Universidad de Alicante.

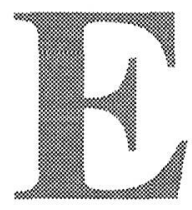

1 objetivo del artículo consiste en el estudio de la trayectoria que las mujeres españolas recorrieron durante dos décadas, los años 30 y 40 , que han sido básicas y decisivas en el proceso de toma de conciencia de su propia personalidad, determinando en buena parte a la mujer actual, con momentos de esplendor, durante la República, y de miseria, durante el Franquismo, especialmente sus primeros años.

La posición y el debate de la mujer en la sociedad española han ido cambiando a lo largo del tiempo, con la misma trayectoria que en otros países del entorno europeo y americano pero, en cambio, el recorrido y los logros se han ido produciendo de forma muy lenta y tortuosa, con avances y retrocesos. En Gran Bretaña y Estados Unidos, el movimiento feminista ya estaba organizado y con una importante presencia pública a mediados del siglo XIX ${ }^{1}$.

En España, por el contrario, a finales del siglo XIX, todavía no existía ni una polémica real sobre cuestiones feministas ni grupos o entidades feministas bien organizados y con un programa de reformas. En los primeros años del siglo XX, el feminismo empezó a abrirse un hueco, cada vez con mayor frecuencia, en la prensa, mediante artícu-

\footnotetext{
Véase la serie de reformas que se producen por estos años en Gran Bretaña y los Estados Unidos y otros países europeos en ALBA, V. Historia social de la mujer. Plaza y Janés, Barcelona, 1974, pp. 177-203. DE VEGA, E. La mujer en la Historia. Anaya, Madrid, 1992, pp. 48-85. DUBY, G.; PERROT, M. Historia de las mujeres en Occidente. Taurus, Madrid, 1993, vol. 5. EVANS, R.J. Las feministas. Los movimientos de emancipación de la mujer en Europa, América y Australasia. 1840-1920. Siglo XXI, Madrid, 1980. Para el caso español, SCANLON, G. M. La polémica feminista en la España Contemporánea. 1868-1974. Akal, Madrid, 1986, pp. 3-4. FAGOAGA, C. La voz y el voto de las mujeres. El sufragismo en España, 1877-1931. Icaria, Barcelona, 1985. FOLGUERA, P. (comp.) El feminismo en España: dos siglos de historia. Fundación Pablo Iglesias, Madrid, 1988. NASH, M. Mujer, familia y trabajo en España (1875-1936). Anthropos, Barcelona, 1983.
} 
los, y en conferencias públicas de forma que a fines de los años 10 , se organizan los primeros grupos feministas con un programa claro de reformas. Es evidente el retraso del feminismo español, en relación a otros países, debido a la propia evolución socioeconómica y política española.

El movimiento feminista, como impulso de mejora de la posición de la mujer, surge básicamente de las doctrinas de la Revolución Francesa y los cambios económicos que produjo la Revolución Industrial; además, los países pioneros en la aparición del feminismo eran protestantes, con una generalizada industrialización y una gran tradición librepensadora. En España, la incipiente, débil y disgregada industrialización del XIX, la escasa fuerza de la Ilustración, la hostilidad del conservadurismo católico hacia las ideas igualitarias y la estructura e intereses sociopolíticos explican, en cierta medida, los serios problemas que ha tenido que afrontar el feminismo como factor opuesto a la tradición, llegando a ser considerado como una herejía, desatada por los enemigos de la fe y de España, con el objetivo de destruir la vida familiar y social. Con la Revolución de 1868 se cuestionaba, por primera vez, el ideal tradicional sobre las funciones que debían desarrollar las mujeres. Con la Restauración de 1875 se produce un parón y un retorno a la situación existente con anterioridad a 1868, jugando la Iglesia un papel destacado, al recuperar su influencia sobre la educación y la vida civil.

La acusada crispación política y social existente en las cuatro primeras décadas del siglo XX, y especialmente durante los años 30 , perjudicó el desarrollo del feminismo, calificado de irrelevante y burgués por la izquierda con la única alternativa que ofrecía una sociedad socialista o anarquista, mientras que la derecha, tras una inicial desconfianza, decidió apoderarse del mismo para usarlo en su propio beneficio. Con la II República (1931-36/39), las mujeres consiguen, al menos teóricamente, sus aspiraciones más elementales; durante la Guerra Civil se registra una radicalización de las posiciones de las mujeres en el territorio leal a la República, mientras que en la zona sublevada se inicia la marea antirreformista. De nuevo, en 1939, con la extensión del régimen franquista a todo el Estado, se restaura el ideal tradicional de la mujer, con una férrea vigencia hasta principios de los años 60 , momento en que empieza a ser cuestionado.

\section{LA MUJER DURANTE LA REPÚBLICA: REFORMAS Y FRENOS}

Los últimos años de la Monarquía de Alfonso XIII se desarrollaron bajo la dictadura primorriverista, con un interés paternalista por los 
derechos de la mujer ${ }^{2}$. Aunque se hicieron algunas concesiones, como es el caso de las leyes de protección al trabajo, facilidades para cursar estudios universitarios, posibilidad de acceso a los gobiernos municipales, un derecho de voto restringuido, a nivel local, a las mujeres que eran cabeza de familia -inspirado en la Italia mussoliniana-, nombramiento de algunas mujeres en la Asamblea Consultiva, entre otros aspectos, los avances producidos en la posición de la mujer seguían siendo escasos.

En abril de 1931, cuando se proclama la II República ${ }^{3}$, se inicia una nueva etapa, con una decidida voluntad de reformar estructuralmente España para asemejarse a las democracias parlamentarias europeas. Para las mujeres también se abre un horizonte nuevo, con la posibilidad real de llevar a la práctica sus principales aspiraciones ${ }^{4}$. En este contexto, resalta el carácter urgente de las primeras medidas, la concesión del derecho de voto y los acuerdos sobre derecho de familia. En efecto, en los 8 meses de mandato del Gobierno Provisional (abrildiciembre 1931) no se frustraron estas esperanzas, con las siguientes disposiciones: nombramiento de Victoria Kent como Directora General de Prisiones, acceso de la mujer a los Tribunales de Justicia en asuntos relativos a crímenes pasionales, a los cargos de notarios y registradores, posibilidad de ser candidato a las Diputaciones,...

2 GARCÍA BASAURI, M. «La mujer en el reinado de Alfonso XIII. Una aproximación al primer movimiento feminista español», en Tiempo de Historia, ${ }^{\circ} 46$, setiembre 1978, pp. 26-39.

3 El sistema de partidos vigente durante la República estaba integrado por los partidos republicanos -con un amplio aspectro ideológico, desde el centro-izquierda al centro-derecha-, las entidades obreras y los partidos antirrepublicanos -rechazaban la República o la asumían transitoriamente, como bloque antirreformista, ultraconservador y tradicionalista-.

Véase ARTOLA, M. Partidos y programas políticos. 1808-1936. Taurus, Madrid, 1969. MONTERO, J.R. La Ceda. El catolicismo social y político en la II República. Ed. de la Revista del Trabajo, Madrid, 1977. PRESTON, P. La destrucción de la democracia en España. Alianza, Madrid, 1987. VARELA, S. Partidos y parlamento en la II República. Ariel, Barcelona, 1978.

4 CAPEL, R.M. El sufragio femenino en la Segunda República. Horas, Madrid, 1992. GARCÍA MÉNDEZ, E. La actuación de la mujer en las Cortes de la Segunda República. Ministerio de Cultura, Madrid, 1979. GONZÁLEZ CASTILLEJO, Ma.J. La Nueva Historia. Mujer, vida cotidiana y esfera pública en Málaga, 193I-36. Atenea-Universidad, Málaga, 199J. NASH, M. «Política, condició social i mobilització femenina: les dones a la Segona República i a la Guerra Civil», en AA.VV. Mes enllà del silenci. Generalitat de Catalunya, BarceIona, 1988, pp. 243-264. NÚÑEZ PÉREZ, Ma.G. Madrid 1931. Mujeres entre la permanencia y el cambio. Ed. Horas-Dirección General de la Mujer de la Comunidad de Madrid, Madrid, 1993. 
La Constitución republicana (9 diciembre 1931) fue una pieza importante para el avance de las aspiraciones femeninas, al reconocer una serie de derechos: igualdad de sexos y derechos, prohibición de la discriminación laboral, protección del trabajo de las mujeres, seguro de maternidad ${ }^{5}$, derecho de voto y a ser elegible para las mayores de 23 años y la reforma de la familia, con el reconocimiento del matrimonio civil y el divorcio. Sin embargo, ningún artículo recogía la abolición de la prostitución ${ }^{6}$, defendida incesantemente desde el movimiento obrero. La ley del divorcio ${ }^{7}$ ( 2 marzo 1932), precedida de un debate muy intenso, fue una de las innovaciones más discutidas de la República, a pesar de ser España e Italia los dos únicos países europeos más importantes que en 1931 carecían de él.

La concesión del voto femenino (artículo 34 de la Constitución -1 octubre 1931-), fue especialmente polémico ${ }^{8}$. Algunas mujeres socialistas, como Margarita Nelken y María Martínez Sierra, insistían básicamente en el peligro que representaban la mayoría de las mujeres españolas -más de la mitad del cuerpo electoral- para la República, al estar bajo el amparo y control de la Iglesia Católica y estar educadas bajo unas coordenadas que malconsideraban la libertad, de la que debían defenderse; además, también estaban seriamente preocupadas por las escasas aspiraciones de las mujeres de clase alta, opositoras al divorcio y recelosas de algunas cuestiones como, por ejemplo, las madres solteras. Por todos estos prejuicios, estaban convencidas que la mejor solución era acudir a la legislación para que determinara el cambio de costumbres y actitudes morales.

5 El avance del seguro de maternidad fue muy lento, al resistirse muchas obreras a cotizar o al ser solteras, lo consideran injurioso para su honor.

- Las disposiciones relativas a la prostitución se posponían para una futura ley de sanidad. En 1935 se abolieron las leyes referentes a la prostitución.

7 La ley del divorcio completaba una serie de medidas anticlericales recogidas en la Constitución para controlar el poder de la lglesia en la vida pública y privada, con una férrea oposición de los sectores católicos.

El divorcio era una cuestión considerada como razonable, aunque muchos de los hombres de «pensamiento avanzado» arguían ciertos reparos, como un temor a que las costumbres españolas se decantaran hacia el repudio, imitando el estilo oriental. En la práctica, el impacto del divorcio fue reducido, limitado a las grandes ciudades y regiones de voto izquierdista.

* Para los radicales y muchos socialistas, «las mujeres están sometidas al cura» y una buena parte de los republicanos defendían posturas misóginas.

Fue decisivo y significativo el enfrentamiento que sostuvieron las 3 primeras mujeres en lograr escaño parlamentario: la socialista Margarita Nelken rechazaba su aprobación, la radical-socialista Victoria Kent aplazaba su concesión y la radical Clara Campoamor exigía un inmediato otorgamiento, arrastrando el voto favorable de los diputados socialistas.

Véase CAPEL, R.M. El sufragio femenino en la Segunda República. Universidad de Granada, Granada, 1975. 
La corriente de pensamiento democrático defendía, desde hacía tiempo, una serie de reivindicaciones femeninas: denuncia de la situación conyugal y sexual, protestas contra la desigualdad cultural y jurídica entre los maridos, la tolerancia ante el adulterio del marido, la prostitución,...

Los partidos republicanos demostraban poco interés en las cuestiones femeninas, pero, a pesar de ello, se organizaron grupos femeninos como la Agrupación Unión Republicana Femenina. En cambio, las demandas femeninas eran atendidas o al menos lograban un mayor respaldo entre las organizaciones de izquierda y de derecha, aunque con planteamientos y diferencias sustanciales.

Las mujeres afiliadas en organizaciones de izquierda aprovecharon el ambiente favorable del nuevo contexto para difundir y defender sus planteamientos ${ }^{9}$. El radicalismo revolucionario de los anarquistas consideraba a la mujer en igualdad de condiciones que el hombre, estando ambos totalmente compenetrados por y para los mismos ideales, derechos y deberes, animándola continuamente a la participación activa en la lucha revolucionaria; se luchaba por el reconocimiento del amor libre, el desarrollo de los métodos anticonceptivos, la «liberación de la esclavitud del hogar»... Se trabajó en favor de la integración femenina en los sindicatos e incluso creando ramas casi femeninas, como el servicio doméstico. Paralelamente, la propaganda actuaba sobre el hombre para que abandonara sus ideas tradicionales sobre la mujer y los fuertes y peyorativos prejuicios existentes.

Desde las filas socialistas se denunciaba el oportunismo político de la Iglesia por su campaña de proselitismo entre los obreros y las mujeres, recordándoles constantemente el tradicional antifeminismo de la Iglesia y su nula defensa de los derechos de la mujer trabajadora. Los socialistas defendían celosamente la igualdad legal de los dos sexos y para ello creían necesario un cambio de mentalidad, de ahí el despliegue de una amplia e intensa campaña propagandística, tratando de convencer a la mujer, tanto de clase media como obrera, que los socialistas eran los únicos que podían ofrecer una verdadera igualdad. En cambio, la realidad ofrecía una situación bastante distinta a la teórica; un importante grupo de mujeres dedicadas a la política, tanto de izquierda como de derecha ${ }^{10}$, pensaban que la contribución femenina a la política debía ser «esencialmente femenina» e incluso se dudaba de la capacidad de la mujer para ejercer adecuada y plenamente algunas funciones.

9 NASH, M. «La problemática de la mujer y el movimiento obrero», en Teoría y práctica del movimiento obrero en España. 1900-1936. Fernando Torres, Valencia, 1979, pp. 242-279. Idem. Mujer y movimiento obrero en España. 1931-39. Fontamara, Barcelona, 1968.

10 Véase en SCANLON, G.M. op. cit., p. 286, la coincidencia de pensamiento que tenían la diputada socialista María Martínez Sierra y la secretaria política de Acción Popular y vicesecretaria del consejo nacional de la CEDA, Pilar Velasco, a pesar de estar en polos ideológicos contrapuestos. 
Las organizaciones políticas conservadoras" ${ }^{11}$, especialmente la extrema derecha, junto con la estrecha colaboración de la Iglesia Católica, mantenían y defendían planteamientos distintos para la mujer, al igual que se oponían al programa de reformas que representaba la República, organizando una campaña para contrarrestar los «peligros de la ideología revolucionaria», de acuerdo con la línea tradicional del feminismo católico. Consideran que la mujer es distinta al hombre, estando protegida por éste porque necesita estar acompañada y sostenida, pero, ante todo, era totalmente necesario el abandono de la creencia «estúpida» y «absurda» del feminismo que conlleva la masculinización de la mujer, abandonando su «misión familiar» y la participación en la vida pública, todo ello en el contexto de la defensa y/o recuperación de los valores tradicionales del Catolicismo frente a la legislación laica republicana. Para ello, se revitaliza Acción Católica, se ponen en práctica los principios del socialismo cristiano católico y se fundan diversas entidades, dotadas de bibliotecas y los recursos necesarios -excursiones, actividades deportivas,...- para intentar transformar el «ambiente pagano, paganizador, sectario y anticristiano» existente: la Juventud Católica Femenina y la Juventud Agrícola Católica Femenina -filial de la primera como guía espiritual, social y profesional de las jóvenes campesinas-. En Madrid se crea el Centro de Cultura Superior Femenina como avanzadilla de una serie de futuras instituciones que debían preparar y «formar» a la élite para posteriormente preservar el alma de la mujer íntegra y limpia de contaminación. Pretendía ser una especie de Universidad Femenina para corregir la «deformación» de la mujer, atribuida a la coeducación y la desaparición de la formación religiosa y doméstica en los centros escolares. Por ello, también aparecieron Círculos de Estudios, con cursillos semanales donde se estudiaba y reflexionaba sobre estas cuestiones.

Por el contrario, la Asociación Femenina de Acción Nacional, fundada en Madrid en el otoño de 1931, tenía una orientación más claramente política, con ramificaciones por distintas provincias y secciones encargadas de actividades específicas, como manifestaciones culturales, revisión del censo electoral y propaganda. Socialmente, la mayo-

11 BAENA LUQUE, E. «La mujer conservadora sevillana. Origen y actividad de «Acción Ciudadana de la Mujer (1931-36)», en La mujer en Andalucía. Universidad de Granada, Granada, 1990, vol. I, pp. 329-339. DUPLAA, C. «Les dones i el pensament conservador català contemporani», en Mes enllà del silenci. Generalitat de Catalunya, Barcelona, 1988. GONZÁLEZ CASTILLEJO, $\mathrm{M}^{\mathrm{a}}$.J. «Literatura religiosa y mentalidad femenina: el discurso de la sumisión en la II República», en Mujeres y Hombres en la formación del pensamiento occidental, Universidad Autónoma de Madrid, Madrid, 1989, vol II, pp. 343-354. Extraordinariamente interesantes son las páginas 656-692 de MONTERO, J.R. op. cit. para el conocimiento de los movimientos femeninos conservadores. 
ría de sus miembros pertenecían a la clase media y alta, haciendo también proselitismo entre las obreras -se crearon escuelas nocturnas para impartir enseñanza religiosa y doméstica-. La organización femenina estaba estrechamente vinculada a la organización masculina, con una intervención constante en las actividades femeninas. Según recoge Geraldine M. Scanlon ${ }^{12}$ «el grupo femenino de Murcia, por ejemplo, no se decidió a intensificar su labor propagandística y a comenzar sus visitas a los pueblos hasta haber solicitado permiso, y tuvo buen cuidado en dejar constancia de que aquella labor la realizaban siempre con la autorización del Comité de Caballeros».

El 29 de octubre de 1933 se constituía en Madrid, durante el transcurso de un acto público, Falange Española ${ }^{13}$, una organización política alternativa al sistema democrático representativo, con un marcado carácter conservador, autoritario y una férrea oposición a la trayectoria desarrollada por la República. Rechazaba tajantemente los avances concedidos a las mujeres, especialmente todos aquellos aspectos que «atentaban» contra la familia y las «costumbres tradicionales de la Patria», como era el divorcio. En los primeros meses de vida de la Organización, su propio fundador, José Antonio Primo de Rivera, se opuso a la admisión de mujeres; la violencia política ${ }^{14}$ existente, y que iba a rodear las actividades falangistas, creaba un ambiente y una dinámica poco favorables para la presencia femenina en el seno de Falange.

Como contrapartida, se permitió la afiliación femenina al incipiente Sindicato Español Universitario, SEU, de donde surgiría, un año más tarde en Madrid, la «primera Sección Femenina de Falange» ${ }^{15}$, coincidiendo con las primeras detenciones de militantes falangistas y las dificultades en el desarrollo de la Organización. En ese nuevo contexto, la presencia, participación y colaboración femeninas era necesaria, y en muchos casos insustituible, para prestar ayuda y apoyo a los

12 SCANLON, G.M. op. cit. p. 285.

13 CHUECA, R. El fascismo en los comienzos del régimen de Franco. Un estudio sobre FETJONS. CIS, Madrid, 1983. ELLWOOD, Sh. Prietas las filas. Historia de Falange Española, 1933-1983. Crítica, Barcelona, 1984.

14 La vida sociopolítica de la II República se caracteriza por el enfrentamiento dialéctico constante entre la izquierda y la derecha. Varias sublevaciones antirrepublicanas intentaron acabar con los programas reformistas y con el propio régimen republicano. La violencia política y las detenciones eran una constante de la vida cotidiana.

Véase GONZÁLEZ CALLEJA, E. «Camisas de fuerza: fascismo y paramilitarización», en Historia Contemporánea, $\mathrm{n}^{\circ} 11$, Bilbao 1994, pp. 55-81.

15 GALLEGO MÉNDEZ, Ma .T. Mujer, Falange y Franquismo. Taurus, Madrid, 1983. JARNE, A. La Secció Femenina a LLeida. Pagès editors, Lleida, 1991. SÁNCHEZ LÓPEZ, R. Mujer española, una sombra de destino en lo universal. Trayectoria histórica de Sección Femenina de Falange (1934-1977). Universidad de Murcia, Murcia, 1990. SUÁREZ FERNÁNDEZ, L (Coor.). Crónica de la Sección Femenina y su tiempo. Nueva Andadura, Madrid, 1993 
«presos» del Partido y a los familiares de los «caídos», recaudar recursos económicos y difundir propaganda. De esta forma, la Sección Femenina aparecía en la escena pública como puntal de apoyo de los «camaradas» en el enfrentamiento que éstos mantenían con la legalidad y el orden político vigentes.

La agudización de las tensiónes políticas y sociales en los meses previos al estallido de la guerra civil concienció a Falange, los anarquistas y los comunistas de la creciente importancia política que estaba adquiriendo la mujer y la necesidad de organizarlas adecuadamente. Posiblemente fuera la dirigente comunista Dolores Ibárruri, en un momento de rápido e imparable crecimiento del PCE, quien más se destacara en alentar y promover la movilización activa de las mujeres contra la reacción fascista. En este sentido, defendía con ahínco la renovación completa de las costumbres, el acceso de la mujer a la dirección de sindicatos y partidos políticos e incluso ejercer la tercera parte de las concejalías locales.

No obstante, como afirma Geraldine M. Scanlon ${ }^{16}$, muy posiblemente la gran mayoría de las mujeres españolas continuaron obedeciendo los dictados de su conciencia católica, por lo que las reformas republicanas eran un derecho y una posibilidad al alcance de las mujeres, pero que no necesariamente debían llevarlas a la práctica, como era el caso del divorcio, el matrimonio civil,... La pervivencia tenaz de los prejuicios tradicionales y los recelos al pasar de la teoría a la práctica en amplios sectores masculinos que habían defendido los derechos de la mujer, incluso hasta entre los revolucionarios más radicales, pone de manifiesto el ambiente y la actitud entre los núcleos conservadores y de extrema derecha. A pesar de los cambios legislativos introducidos por la República, estaba pendiente el cambio de las mentalidades y eso no podía hacerse por decreto sino por voluntad propia. Además, debido a la heterogénea actitud del colectivo femenino en defensa de sus intereses, los avances no fueron mayores, autolimitándolos la propia experiencia.

\section{LA GUERRA CIVIL: UNA MUJER REVOLUCIONARIA}

El estallido de la Guerra Civil produjo un cambio radical y profundo en la vida política, social, económica y cultural del Estado; las mujeres y sus aspiraciones no pudieron quedarse al margen al formar parte de esa realidad ${ }^{17}$. Las nuevas condiciones favorecieron en el territo-

17 Véase en ALBA, V. op. cit. pp. 203-227 los postulados ideológicos de las organizaciones 
rio leal a la República la puesta en práctica de los logros obtenidos desde la primavera de 1931, mientras que en la zona sublevada se producía la situación inversa, con el avance de la marea antirreformista.

Con la aplicación de la revolución socioeconómica en el territorio republicano y la movilización masculina para ir al frente, la mujer pasó a ocupar y desempeñar las tareas que quedaban desatendidas en el aparato productivo y en la dirección de las instituciones, organizaciones y todo tipo de servicios, además de realizar cualquier actividad, desde la confección de uniformes a la prestación de servicios sanitarios. En este contexto, el ideal de la mujer trabajadora se convirtió en una necesidad práctica; las mujeres se concienciaron sólidamente de la importancia de la lucha antifascista y el importante papel que podían y debían tener. La propaganda ${ }^{18}$, por todos los medios disponibles -prensa, radio, cartelería y actos públicos- fue un elemento básico en todo momento, distribuyendo por doquier -incluso en el medio rural- la imagen de una mujer activa hasta tal punto que se llegó a identificarla con el triunfo de la República junto con la proliferación de numerosos grupos femeninos y con ellos una amplia gama de actividades. La advertencia del peligro ante un hipotético triunfo de los sublevados, que imitarían la experiencia y los modelos alemán e italiano, la represión femenina en el territorio franquista y la alabanza del bienestar que las mujeres disfrutaban en la Unión Soviética eran los recursos para movilizar y persuadir más habituales.

La participación femenina en el campo militar fue la primera actividad marcadamente masculina que se registra a partir del 18 de julio de 1936, favorecida por la desorganización y euforia de los primeros días, mediante la figura de la miliciana; en ciudades importantes, como Barcelona y Madrid, las mujeres se comprometieron activamente en la lucha contra los rebeldes. En contrapartida, fueron apareciendo figuras heroicas y mártires, con un gran calado propagandístico. Con el paso del tiempo, la organización y disciplina del ejército republicano delimitó las funciones masculinas y femeninas en aras de una mayor eficacia aunque con resistencias: el hombre iba al frente y la mujer a la retaguardia.

La organización femenina en la retaguardia estaba en manos de distintas entidades femeninas, a su vez estrechamente vinculadas a un partido político o sindicato, aunque se solía decir estar abiertos a cualquier tendencia ideológica. Disponían de prensa propia, entre otros recursos propagandísticos, para difundir y alentar en sus consignas re-

1. Véase una muestra significativa en AA.VV. Las mujeres en la guerra civil. Ministerio de Cultura, Salamanca, 1989. 
lativas al aprovechamiento integral de toda la capacidad femenina. Hubo trasvase de afiliación política en busca, por lo general, de un mayor dinamismo, como solía ocurrir con los desplazamientos desde las filas socialistas a las comunistas. Los grupos femeninos más activos y, por tanto, con una mayor labor, eran los comunistas -favorecidos desde el Gobierno con la presencia de ministros comunistas-y los anarquistas; en cambio, los republicanos y los socialistas tuvieron escasa relevancia, especialmente los primeros. Un importante problema fue la existencia, al igual que en las filas masculinas, de rivalidades partidistas básicamente entre los comunistas y anarquistas, foco de tensiones y ausencia de unidad frente al enemigo. Las principales actividades que realizaron consistieron en la recaudación de recursos económicos y productos para el frente y los refugiados, la creación de talleres, guarderías y centros de acogida, organización de cursillos técnicos para capacitar a las mujeres en los trabajos industriales y en servicios sociales y sanitarios junto con una amplia gama de actividades culturales acompañada de instalaciones adecuadas. Sobresale las celebraciones de las «semana de la mujer antifascista», orientadas hacia la difusión de consignas propagandísticas, generalmente coincidiendo con momentos críticos.

Mujeres Antifascistas era la organización femenina afín al PCE, creada en 1933 con su ramificación catalana de la Unió de Dones de Catalunya; a nivel juvenil estaba la Unión de Muchachas, controlada por las Juventudes Comunistas y Socialistas y la Aliança Nacional de la Dona Jove era su homóloga catalana. Las mujeres anarquistas estaban organizadas en Mujeres Libres ${ }^{19}$, desde el verano de 1936 a partir de una serie de grupos existentes con anterioridad.

Las mujeres anarquistas insistían especialmente en dirigir la preparación técnica como una forma para formar profesionalmente a la mujer y poder ser independiente del hombre, en lugar de ser un mero sustitutivo mientras durase la guerra. Paralelamente se incentivaba la participación activa y consciente en la vida política y social. Con la creación de los Institutos de Trabajo se pretendía proporcionar al mismo tiempo una educación social, cultural y técnica. La reforma sexual -fueron pioneras en el inicio de la revolución sexual en España--, el amor libre, la abolición de la prostitución ${ }^{20}$, los «matrimonios confederales», las mayores facilidades en los métodos anticonceptivos, el aborto..., eran cuestiones especialmente defendidas por las mujeres anarquistas, pero

La prostitución y las relaciones sexuales en el frente aumentaron extraordinariamente durante la guerra -incluso se llegaron a colectivizar algunos burdeles-, siendo objeto de frecuentes comentarios y sátiras. 
la prioridad absoluta de la lucha por la libertad restaba protagonismo y atención. Por ello, el aborto y el control de la natalidad fueron dos parcelas escasamente atendidas y, aún así, el aborto se legalizó en noviembre de 1936 al acceder Federica Montseny a la cartera de sanidad.

El Secretariado Femenino del Partido Obrero de Unificación Marxista (POUM), Socorro Rojo Internacional (SRI) y Solidaridad Internacional Antifascista (SIA) eran otras entidades que contaban con una importante presencia femenina en sus filas.

En general, no puede afirmarse que los cambios en las costumbres y en las actitudes introducidos durante la guerra produjeron una verdadera liberación de la mujer; al igual que había ocurrido entre 19311936, las mujeres respondieron de forma desigual a los llamamientos ante la pertinaz persistencia de una mentalidad tradicional tanto en hombres como en mujeres. Sobresale la moderación de la propaganda comunista -la «liberación» femenina sería un premio después de la guerra- frente al mayor radicalismo y apuesta decidida del anarquismo; en determinados ambientes preocupaba bastante que la mujer quitara protagonismo al hombre, pero, ante todo, el puesto de trabajo y en este sentido, las mujeres socialistas fueron las más tibias.

\section{6-50: EL FRANQUISMO Y LA MUJER NACIONAL-SINDICALISTA}

A partir de la primera Sección Femenina creada en Madrid en 1934, la Organización se fue extendiendo progresivamente por el resto del Estado desde el centro-norte peninsular. Entre enero y julio de 1936 habían desarrollado su actividad clandestinamente -escondida de armas, confección de camisas y banderas, mensajeras con los prisioneros- debido a la ilegalización de Falange y el encarcelamiento de sus principales dirigentes.

En el verano de 1936, con la sublevación militar contra la Repúbli$\mathrm{ca}$, desde las filas de la Sección Femenina ${ }^{21}$ las mujeres realizaron distintas tareas en la retaguardia, al igual que sus homólogas republicanas, con unas funciones reducidas, y esencialmente condicionadas por las circunstancias bélicas del momento, sin representar un avance de las posiciones femeninas: organización de talleres, lavanderías, servicios sanitarios, mantenimiento de la moral de la tropa,... La función bélica de las mujeres estaba mejor organizada que en la zona republicana, subordinada a las autoridades militares, en el marco de unidad y

21 ALCALDE, C. La mujer en la guerra civil. Cambio 16, Madrid, 1976. DEL RINCÓN GARCÍA, F. «Mujeres azules en la guerra civil», en Estudis d'Història Contemporània del País Valencià, $\mathrm{n}^{\circ} 7$, Universitat de València. 
disciplina de la propia Sección Femenina. Cabe recordar la estructura jerárquica y de absoluta subordinación a la rama masculina de Falange, semejante a una estructura cuartelera, hasta tal punto que era necesaria la obediencia al superior inmediato, sin la menor posibilidad de colaboración entre mandos iguales y en ningún momento se cuestionaba la supremacía de la autoridad masculina. Al contrario que en el territorio republicano, los hombres no temían ser sustituidos por las mujeres, plenamente conscientes de realizar una tarea exclusivamente coyuntural -mientras durase la guerra- para regresar luego al lugar que les correspondía por su propia naturaleza. Era muy remota la posibilidad de la existencia de la «mujer combatiente» y así, por ejemplo, como recoge Geraldine M. Scanlon ${ }^{22}$, todavía en 1963, las falangistas se escandalizaban de recordar a la «mujer-soldado».

Con un marcado carácter asistencial-caritativo se creaba en otoño de 1936 el Auxilio de Invierno, posteriormente rebautizado como Auxilio Social, inspirado en el Winterhilfe alemán. Con el Decreto de Unificación entre falangistas y tradicionalistas -19 abril 1937-, Auxilio Social tenía por objetivo conseguir el control de los servicios sociales del Nuevo Estado, estructurándose en una serie de departamentos: Obra Nacional-Sindicalista de Protección a la Madre y al Niño, Auxilio Social al Enfermo, Fomento del Trabajo Familiar, Defensa de la Vejez y Obra del Hogar Nacional-Sindicalista; de todos ellos, el más importante era el primero, dada la gran importancia que se concedía a todo lo relacionado con la familia.

En abril de 1939, con el control de todo el Estado por los sublevados, se produce la definitiva desaparición de la República, con un intenso rechazo, desprecio y crítica a las ideas, valores y reformas defendidas y encarnadas por la República, incluidos los avances y mejoras conseguidos y/o concedidos a las mujeres. Posiblemente el aspecto más destacable sea la eliminación de la igualdad jurídica y la recuperación de la tradición que conllevaba el retorno-reclusión de la mujer en el interior de su casa, el modelo de la «mujer de la vieja España» y las campañas de descrédito del feminismo. Las principales jerarquías masculinas del Partido y sus ideólogos, los medios de comunicación y las propias dirigentes femeninas ${ }^{23}$ se encargaron de difundirlo y

22 SCANLON, G.M. op. cit. p. 318.

23. Son muy significativas las intervenciones de las principales jerarquías de FET y de las JONS en los Consejos Nacionales que, en enero de cada año, celebraba la Sección Femenina, en los que se hacía balance del año anterior y se programaba el año en curso, así como editoriales y artículos publicados en la prensa de la época. Véase el rotativo Arriba, órgano oficial de FET y de las JONS, así como las revistas oficiales de la Sección Femenina $Y$, Consigna y Medina. PRIMO DE RIVERA, P. Recuerdos de una vida. Dyrsa, Madrid, 1983. Idem, Escritos, circulares, discursos. Madrid, s/f. 
defenderlo, especialmente durante el período 1939-45, manteniendo siempre los mismos planteamientos, con un especial énfasis en aquellas zonas del Estado que habían sido fieles al régimen republicano y donde la población era, desde el punto de vista ideológico, marcadamente de centro-izquierda. El proceso antirreformista y derogatorio de la legislación republicana se inició con la sublevación militar, extendiéndose a los territorios que las tropas iban ocupando: el matrimonio civil, el divorcio, restablecimiento del Código Civil de $1889^{24}$, el aborto y los métodos anticonceptivos, reforma del código penal reinstaurando los artículos abolidos por la República, restablecimiento de la legislación laboral anterior a la República, promulgación de leyes protectoras de la familia y la natalidad, penalización del trabajo femenino y veto al acceso a determinados empleos, supresión de la coeducación..., entre otros muchos aspectos ${ }^{25}$. Paradójicamente, la ilegalización de la prostitución se producía en 1956, a pesar de la prioridad que el Régimen tenía en proteger la familia y defender la moralidad pública; se permitió el voto femenino en el Referendum Nacional de julio de 1947 sobre la Ley de Sucesión aunque ésta rechazaba una sucesora femenina.

Los movimientos fascistas, en sus distintas variantes, eran antifeministas mientras que consideraban las cualidades varoniles como valores morales ${ }^{26}$. A pesar de ello, para gobernar necesitaban el apoyo femenino de ahí la organización de las mujeres en escuadras, grupos de choque o secciones femeninas, mediante el nacionalismo, el tradicionalismo o incluso desafiando los valores cristianos.

La Sección Femenina recibe el «encargo» oficial de «movilizar»y «formar» política y socialmente a todas las mujeres españolas, en todas sus edades -niña, joven y adulta- y campos de actuación -trabajo, cultura, deportes, educación,...- como «misión» exclusiva ${ }^{27}$; de esta forma se convierte en la única organización oficial femenina del Régimen. Acción Católica, integrada por cuatro ramas, masculina y feme-

Véase en el capítulo 3 de SCANLON, G.M. op. cit. «la posición legal de la mujer».

Véase para un mayor detalle SCANLON, G.M. op. cit. pp. 320-322.

MACCIOCCHI, $\mathbf{M}^{a}$.A. Elementos para un análisis del fascismo. El Viejo Topo, Madrid, 1977. REICH, W. La psicología de masas del fascismo. FCE, México, 1973. Para el encuadramiento de juventudes y mujeres para el caso italiano, CUTRUFELLI, M.A. y otras. Piccole italiane. Un raggiro durato vent'anni. Edizioni Anabasi, Milano, 1994. ADDIS SABA, M. (ed). La corporazione delle donne. Vallechi editore, Firenze, 1988. Para el caso alemán, JILL, S. The nazi organisation of women. Croom Helm, London, 1981. Para el caso portugués, LOPES DE ARRIAGA. Mocidade portuguesa. Breve historia de una organización salazarista. Terra Liure, Lisboa, 1976.

27 La Ley de la Jefatura del Estado del 28/12/1939 establecía la misión política que debía desarrollar la Sección Femenina como Delegación Nacional de FET y de las JONS. 
nina, a su vez subdivididas en adultos y juventudes, realizaba tareas semejantes a las de la Sección Femenina, pero sin ningún carácter oficial, especialmente en materia educativa, con un sustrato ideológico prácticamente idéntico. No obstante, había un reforzamiento de algunos valores esencialmente católicos, como la ayuda al prójimo, al necesitado, la caridad,... Pilar Bellosilla, Vocal de Propaganda del Consejo Superior de Mujeres de Acción Católica insistía en junio de $1946^{28}$ en la gran responsabilidad que tenían las madres en la formación moral y cristiana de sus hijas porque debían mantener la continuidad familiar, la cohesión de las tradiciones cristianas y hogareñas a lo largo del tiempo. Respecto al mundo laboral, si tuvieran que trabajar fuera de casa, debían mantener este espíritu dentro del hogar y el carácter femenino de «abnegación» y «sufrimiento», todo ello presidido por el «modelo de todas las virtudes, encarnado por la Virgen María».

Entre la Iglesia Católica y el Estado hubo una estrecha relación, especialmente manifiesta durante los tres años que duró la guerra y en los años $40^{29}$. En mayo de 1946, el mismo Franco expresaba públicamente ante el Pleno de las Cortes Españolas que «el Estado perfecto para nosotros es el Estado Católico».

La Sección Femenina agrupaba a las mujeres mayores de 17 años, mientras que aquéllas que seguían estudios universitarios pertenecían a la Regiduría de Sección Femenina del Sindicato Español Universitario (SEU); las niñas y jóvenes entre los 7 y los 17 años, eran miembros de la Regiduría Femenina de las Organizaciones Juveniles (agosto 1937diciembre 1940) y posteriormente del Frente de Juventudes (diciembre 1940-abril 1944) ${ }^{30}$. En abril de 1944, la rama femenina de juventudes pasaba bajo la dependencia orgánica y funcional de la Delegación Nacional de la Sección Femenina, tras una dura y tenaz lucha encabezada por la propia Delegada Nacional, Pilar Primo de Rivera, para quien era una «cosa de vida o muerte», contra la resistencia del Frente de Juventudes $^{31}$. El objetivo era la unificación de las ramas femeninas del

Información, 16/6/1946. «La posición de la mujer en el hogar».

29 HERMET, G. Los católicos en la España franquista. CIS, Madrid, 1986. SANCHEZ RECIO, G. De la resurrección de España. Magisterio pastoral y pensamiento político de Enrique Pla y Deniel. Ambito e Instituto de Cultura «Juan Gil-Albert». Valladolid, 1994. TUSSELL, J. Franco y los católicos. La política interior española entre 1945 y 1957. Alianza, Madrid, 1984

30 SÁEZ MARÍN, J. El Frente de Juventudes. Política de juventud en la España de posguerra (1937-60). Siglo XXI, Madrid, 1988.

31 Archivo General de la Administración (en adelante AGA), Cultura-Sección Femenina. Grupo 3, $\mathrm{n}^{\circ} 8, \mathrm{CA}-3$. En julio de 1943 Pilar se dirigía por escrito, desesperada tras las constantes y largas demoras, al Secretario General de FET y de las JONS -Arrese-. Las relaciones entre Sección Femenina y el Frente de Juventudes siempre fueron bastante tensas al intentar éste imponerse -como ocurríía posteriormente en los años 70 , con el intento de reunificar en 
SEU y del Frente de Juventudes en la Sección Femenina al tener ésta el exclusivo «encargo» de Franco, repetido por él mismo en distintas ocasiones, de «formar» al colectivo femenino. La edad infantil era el mejor momento para iniciar una buena y sólida formación. Hasta entonces, las jóvenes falangistas habían estado subordinadas a la rama juvenil masculina aunque las jerarquías eran femeninas, con una relativa dependencia de Sección Femenina.

En la primavera de 1939, recién acabada la guerra, se registra un intenso proceso de ideologización de la población en general y de los distintos sectores que la formaban, entre ellos, el colectivo femenino. El discurso antifeminista falangista de los años 40 ensalza machacona y retóricamente los valores tradicionales de la familia, la maternidad, el hogar, el catolicismo y los principios de servicio, sacrificio, abnegación y obediencia para intentar asegurar la adhesión incondicional de la mujer al Régimen -identificado con el Estado-, contribuir en el fortalecimiento y engrandecimiento de la Patria y, al tiempo, cumplir con el «destino colectivo» innato de toda mujer. Se pretendía la «conquista del hogar y la formación de la mujer y del niño» en el contexto de la consigna joseantoniana de «hogar, trabajo, familia y sindicato», como bases de la España Nacional-Sindicalista, como puso de relieve Franco en la Concentración Nacional del Castillo de La Mota (30 mayo 1939). Falange se autopresenta como una entidad «liberadora» de la opresión que la mujer ha sufrido durante la República y especialmente en la guerra; incluso se acude al término «reconquista», entendido como recuperación de la mujer para trasladarla de nuevo a los valores católi$\cos$ y tradicionales existentes con anterioridad a 1931. La mujer, mediante una doble labor -hacía falta una minoría que dirigiera y unas grandes mayorías que obedecieran con entusiasmo-, debía inspirar al hombre para hacer la Nueva España a través del siguiente mecanismo: el nacional-sindicalismo lo haría el hombre, mientras que la mujer debía hacer al hombre nacional-sindicalista, dándole «esperanza, consuelo e ilusión en el seno del hogar».

La ideología oficial alababa el carácter y peculiaridades femeninas y su «importante» presencia en la vida diaria, según la visión general de la vida que tenía el Partido: paciencia, consuelo, resignación, obediencia, abnegación,... En el fondo, se reduce la mujer a una función marginal e incluso vejatoria, aprovechándose, o al menos intentar hacerlo, de aquellas cualidades innatas en las que el hombre era más «torpe», estableciendo una clara discriminación y relación de inferioridad respecto a éste, basándolas en razones de la propia naturaleza 
humana. Eugenio Montes ${ }^{32}$, Consejero de FET y de las JONS, iba incluso más allá, al manifestar públicamente, en el Consejo Nacional de la Sección Femenina, su total desconfianza en la capacidad femenina para crear cultura; para ello, aportaba una justificación extremadamente sencilla: hasta la fecha ninguna mujer había destacado en este campo a pesar de los numerosos efectivos que se han dedicado a ello. Semejante planteamiento defendía en la relación mujer-trabajo, al afirmar que el hombre era más apto para el trabajo que la mujer, debido a la propia esencia fisiológica femenina, poseedora de un sentido que le impide «entregarse» totalmente junto con el carácter extrovertido del hombre frente al introvertido de la mujer. En cambio, decía que la mujer tenía cosas de las que carecía el hombre, como era el caso del "privilegio» de mandar sobre el cuerpo del hombre. Ante todo, el principal obstáculo reside en la predisposición femenina a la maternidad, equiparada automáticamente como deficiencia para el trabajo. Entendía que la sociedad demandaba a la mujer estar capacitada para el trabajo, pero nunca debía aspirar a ejecutar su capacitación para poder vivir en consonancia con su propia esencia y ser. El Subsecretario de Prensa y Propaganda del Partido ${ }^{33}$ afirmaba que una de las tareas más importantes de la mujer española era participar decisivamente en la «reconstrucción moral de España», entendiéndola como una «tarea formativa en el interior de la vida española», es decir, difundir e intentar arraigar el ideario falangista entre los distintos estratos sociales, básicamente en el seno del núcleo familiar, especialmente en el marido. No obstante, excluía tajantemente la intervención de la mujer en la vida política, en las «funciones rectora y conductora», al concebirla como un gran movimiento de masas y realización colectiva, para poder dedicarse plenamente a las funciones que tenía encomendadas.

La militancia juvenil femenina se estructuraba en tres grupos de edades, compartiendo una misma doctrina, enseñanza y actividad, subordinadas y adecuadas a la edad, al igual que en la rama masculina: margaritas, flechas y flechas azules, de 7 a 10 , de 11 a 14 y de 15 a 17 años respectivamente. Cuando cumplían 17 años se producía el pase a la rama adulta o causar baja definitiva en la Organización. La educación ${ }^{34}$ de las pequeñas falangistas, «las mujeres del mañana», constituía un importante campo de acción, con unas concepciones pedagógi-

\footnotetext{
${ }^{32}$ Arriba, 17/1/1940.

${ }^{33}$ Arriba, 16/1/1940. «Las mujeres de la Falange en la reconstrucción morai de España».

${ }^{34}$ CAMARA VILLAR, G. Nacional-Catolicismo y Escuela. La socialización política del Franquismo (1936-1951). Hesperia, Madrid, 1984. NAVARRO GARCIA, c. La educación y el nacional-catolicismo. Universidad de Castilla-La Mancha, Murcia, 1993. PASTOR I HOMS, Ma.I. La educación femenina de postguerra (1939-45). El caso de Mallorca. Instituto de la Mujer, Madrid, 1984.
} 
cas netamente católicas y un tajante rechazo de la coeducación: con los denominados «planes de formación» en materia política, religiosa, física y cultural en todos los colegios y escuelas públicas y privadas de Primera Enseñanza; en Enseñanza Media se impartían las «enseñanzas del hogar»-desde agosto de 1944-. En las instalaciones de Juventudes -«Casas de Flechas»- las afiliadas de 11 a 14 años que asistían a escuelas públicas y privadas recibían una formación complementaria en las «tardes de enseñanza». Entre los 15-17 años, se podía aprender diversos conocimientos técnicos (idiomas, mecanografía, contabilidad,...). El «Taller deAprendices» completaba la formación de la «Casa de Flechas». En los campamentos, durante las vacaciones veraniegas, las afiliadas simultaneaban el disfrute de la naturaleza con el desarrollo del espíritu de convivencia en comunidad, las actividades recreativas con la formación política y religiosa, el «orden» y la «disciplina» como principales valores. Las estaciones preventoriales tenían por objetivo fortalecer la salud de las niñas debilitadas, recibiendo también una formación política, religiosa y cultural. Las marchas y excursiones eran otro tipo de actividad que completaba los conocimientos de las tardes de enseñanza, por lo general impregnadas de un profundo ambiente religioso y político, con la disertación de algún tema nacionalsindicalista.

Se crearon varias «Escuelas de Mandos», distribuidas por todo el Estado, para preparar a los futuros mandos o incluso reciclar o dar una formación continua y actualizada a los existentes, con una enseñanza especializada; todos los programas incluían la formación religiosa, política, doméstica y física junto a la música. Las alumnas de estas escuelas eran o debían ser la «élite» de la Organización, para adoctrinar posteriormente al resto del colectivo femenino, tanto afiliado como si no lo era, mediante los «planes de formación de la masa». El Estado apoyaba el sistema y con el Decreto del 28 de diciembre de 1939 se declaraba la ciencia doméstica como asignatura obligatoria para todas las alumnas no universitarias. En octubre de 1941 era obligatorio superar un examen de hogar para poder acceder a los estudios universitarios. El Servicio Social, creado durante la guerra, intentaba consolidar el adoctrinamiento doméstico realizado en la escuela y asegurar la misión que cada mujer debía desempeñar en la vida. Era obligatorio su cumplimiento para todas las mujeres de 17 a 35 años para obtener títulos, ejercer una profesión o conseguir un empleo o cualquier cargo público, en 1946 se extendía a las trabajadoras. Se prestó una atención especial a la mujer campesina y obrera, desplazándose equipos de la Sección Femenina para impartir consignas y formación técnica y cultural.

Con la desaparición de la República, el movimiento femenino registra un retroceso, con la recuperación del tradicionalismo católico y 
el alma de la España profunda. La década de los años 40 es una época negra, sin libertad, bajo una total sumisión masculina. La mujer regresa al hogar, la familia, los hijos,... A pesar de los cambios producidos en los años 30, la mentalidad tradicional aún pervivía sólidamente en la conciencia colectiva. La Sección Femenina de FET y de las JONS encarna el nuevo orden y el modelo de mujer oficial que el Régimen pretende imponer; la gran cuestión reside en conocer hasta dónde llegó el sustrato ideológico y cuál fue el grado de auténtica sumisión y obediencia. 